\title{
The relationship between family intimacy and relapse tendency among people who use drugs: a moderated mediation model
}

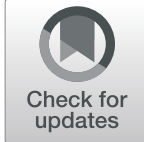

\author{
Zeng Xiaoqing ${ }^{*^{*}}$ (D) Lu Mengyao ${ }^{1}$ and Chen Meirong ${ }^{2}$
}

\begin{abstract}
Background: Drug addiction is difficult to overcome. The relapse rate is high, and the negative impact on individuals, families and society is severe, therefore exploring social psychological mechanisms to reduce relapse has very important theoretical and practical value. However, the underlying mechanism by which the interaction between family and individual factors influences the tendency to relapse remain unclear. Thus, the purpose of this paper is to discuss the relationship between family intimacy and relapse tendency of people who use drugs, as well as the mediating effect of psychological capital and the role of self-efficacy in it.

Methods: A total of 817 male who use drugs were investigated via the Family Intimacy and Adaptability Scale, General Self-Efficacy Scale, Positive Psychological Capital Questionnaire and Relapse Tendency Questionnaire. Using Hayes's process macro carried out moderated mediation analysis.

Results: (1) The average family intimacy score of people who use drugs was low. (2) Family intimacy negatively predicted relapse tendency in people who use drugs. (3) Psychological capital mediated the relationship between family intimacy and relapse tendency. (4) The first half of the indirect effect of family intimacy on relapse tendency was regulated by self-efficacy, compared with the low level of self-efficacy, the psychological capital level with high self-efficacy is higher.

Conclusion: The results of this study suggest that the intimacy between the people who use drugs and their family members should be improved, and the rehabilitation center should take various measures to enhance the psychological capital level and the level of self-efficacy of the people who use drugs, which will be helpful to reduce their relapse tendency.
\end{abstract}

Keywords: Family intimacy, Relapse tendency, Positive psychological capital, Self-efficacy

\section{Background}

More than 35 million people worldwide are currently addicted to drugs, and COVID-19 has created new routes for drug trafficking that increase the risk of drug addiction, making it vital to address this problem [1]. During the COVID-19 pandemic, rehabilitation centres

\footnotetext{
* Correspondence: zxa3701@163.com

${ }^{1}$ School of Psychology, Institute of Psychology, Jiangxi Normal University, Nanchang, China

Full list of author information is available at the end of the article
}

strictly abide by epidemic prevention measures, prohibiting external personnel, including family members, from contacting the people who use drugs (PWUD). The aim is to effectively protect the physical health of PWUD and prevent the combination of COVID-19 and the physiological and psychological effects of drugs from affecting the relapse behaviour of PWUD [2]. Isolation due to COVID-19 may have some impact on family functioning and family intimacy; however, the combined effect on the psychological (anxiety), social (social

\section{BMC}

(c) The Author(s). 2021 Open Access This article is licensed under a Creative Commons Attribution 4.0 International License, which permits use, sharing, adaptation, distribution and reproduction in any medium or format, as long as you give appropriate credit to the original author(s) and the source, provide a link to the Creative Commons licence, and indicate if changes were made. The images or other third party material in this article are included in the article's Creative Commons licence, unless indicated otherwise in a credit line to the material. If material is not included in the article's Creative Commons licence and your intended use is not permitted by statutory regulation or exceeds the permitted use, you will need to obtain permission directly from the copyright holder. To view a copy of this licence, visit http://creativecommons.org/licenses/by/4.0/. The Creative Commons Public Domain Dedication waiver (http://creativecommons.org/publicdomain/zero/1.0/) applies to the data made available in this article, unless otherwise stated in a credit line to the data. 
support, family emotional connection) and behavioural (substance abuse, relapse) of PWUD in complete isolation is currently unknown. Little is known about the psychosocial processes in PWUD, and the theoretical basis of relapse research is still being developed [3, 4]. Participants in this study were all PWUD in compulsory isolation and rehabilitation institutions. PWUD cannot be exposed to drugs during drug rehabilitation. Therefore, relapse tendency can be used as a predictor of relapse behaviour after drug rehabilitation [5]. The purpose of this study was to investigate the relapse tendency of Chinese PWUD in compulsory isolation.

\section{The relationship between family intimacy and relapse tendency}

The family is the smallest unit in a person's social group. The functioning of the family can influence the formation of an individual's character, values and social adaptability $[6,7]$. Family functioning predicts the number of drugs used by individuals [8], the propensity to use drugs [9] and relapse tendency [10]. Family intimacy is one of the dimensions of family functioning and reflects the cohesiveness of emotional ties between family members [11]. It has a strong relationship with substance addictive behaviour [12]. Several studies have shown that closeness among family members is strongly related to relapse in substance abuse; for example, family intimacy negatively predicts the occurrence of drug use problems in individuals [13] while having a dampening effect on alcohol and drug use [14]. High levels of family intimacy can have a protective, stabilizing effect on drug and alcohol problems $[8,15]$, helping individuals cope positively with negative events, increasing psychological repair ability [16], and reducing the occurrence of negative events such as drug use to escape stress [17]. However, poor family emotional connections can increase the risk of substance use [18]. Social support theory [19] suggests that family support is an important component of social support, and individuals with benign family support have higher levels of family functioning [20], enabling individuals to positively cope with and mitigate negative emotions and stress.

\section{The mediating role of psychological capital}

Although family intimacy is an important external factor influencing relapse among PWUD, how family intimacy affects the occurrence of relapse behaviour needs to be further explored. This study found, based on a literature review, that the most important cause of relapse may be negative psychological qualities caused by family influence, such as lack of goals and hope in life, negative approach to life events, difficulty recovering from failure $[21,22]$. Consequently, this study introduces psychological capital to explore its mediating effect on the relation between family intimacy and relapse tendency among PWUD receiving compulsory treatment.

Positive qualities are core elements on which individuals depend for survival and development and are effective for inhibiting the occurrence of behavioural problems [23]. Positive psychological capital is a positive psychological state that individuals exhibit during development and is manifested in four areas: self-efficacy, resilience, hope, and optimism [24]. Several studies in recent years have found that family functioning has an important effect on core components of psychological capital, such as self-efficacy [25] and resilience [26]. The family functioning model [27] suggests that the basic functions of the family provide certain environmental conditions for the healthy development of family members physically and psychosocially and that good family functioning promotes individuals' positive emotional involvement and emotional responses and fosters their positive psychological qualities. Similarly, family intimacy, a measure of family functioning, promotes good communication and problem-solving skills among family members [28] and is able to promote the development of their positive psychological qualities [29]. It has been found that individuals with high family intimacy have significantly higher self-efficacy than those with low family intimacy [30] and are more hopeful and confident about the future and more likely to believe in their ability to refuse drugs [31]. However, poor family intimacy can trigger negative emotions such as low self-esteem and depression [30] and difficulties in emotion regulation, hindering the development of positive psychological qualities [32]. Thus, it is evident that close family emotional ties can enhance the positive psychological capital of PWUD, i.e., enhance their optimism, selfconfidence, resilience, self-efficacy and other positive psychological qualities.

Psychological capital significantly increases individual motivation and proactive and optimistic responses to crisis events and reduces negative emotions and behaviours [33]. Negative psychological qualities and emotions are prevalent in the addiction treatment population, especially the negative emotional responses that arise after withdrawal, which have a significant impact on relapse [34]. The broaden-and-build theory of positive emotions [35] suggests that positive emotions can expand people's thought-action systems, help them develop new problem-solving strategies, and dissipate the effects of the narrowed thought-action repertoire produced by negative emotions. Thus, high levels of psychological capital in PWUD can effectively regulate individuals' negative emotions and problem behaviours [36]. High levels of positive psychological qualities can help individuals quickly regulate stress from external stimuli and develop good social adjustment [37] and can prevent 
relapse behaviour [38]. Therefore, it can be hypothesized that psychological capital can predict relapse behaviour in PWUD.

\section{The moderating role of self-efficacy}

Self-efficacy influences not only individual behaviour [39] but also individual psychological traits [40], and it thus has important moderating effects on individual psychological traits and behaviour. Psychological capital as a psychological trait is naturally influenced by the regulatory effect of self-efficacy. Self-efficacy is the belief that an individual can successfully perform a specific task or behaviour [41], and it can enhance an individual's confidence in his or her ability to obtain desired outcomes and develop positive emotions [42]. It has been found that individuals with high self-efficacy have a strong belief in their ability to accomplish their goals, and this inspires them to have hope in life [8], adopt an optimistic approach to external stimuli [43], and rely on positive qualities such as resilience in difficult situations [44]. High self-efficacy also inhibits the emergence of negative emotions and problem behaviours [45] and promotes the maintenance of a positive mental state [46]. Some studies have also found that self-efficacy is an effective moderator of daily life stress and mental health [47]. PWUD with low self-efficacy often show inaction or a lack of determination and perseverance to overcome difficulties and are more likely to experience "learned helplessness" [48], to deal with problems in a negative frame of mind and to be prone to negative emotions such as anxiety, which affects their overall level of psychological capital [49]. In other words, self-efficacy is a strong predictor of individual coping style, performance level and positive belief when facing difficult problems [50]. Compared with individuals with high levels of family intimacy, individuals with low levels of family intimacy are more likely to have negative emotions, feel pessimistic about life, have a strong sense of inferiority, and lack confidence [51, 52]; individuals with a high level of selfefficacy, which is lacking in those with a low level of family intimacy, have firm confidence, a high sense of achievement and weaker feelings of inferiority [53, 54]. This means that close family affective connections alone are not enough to develop individuals' positive psychological capital, and it is of great significance to investigate the interaction between self-efficacy and family intimacy.

In short, these variables rarely appear in isolation; rather, they appear in groups such that they attract and form building blocks with each other. However, the interaction between family factors and personal factors and the underlying mechanisms remain unclear. Mediation and moderation analyses can be used to determine the relationships between these variables, thus making it a worthy topic for further study. In addition, existing research has mainly focused on persons undergoing voluntary detoxification and community drug treatment in Western countries. Thus, it is necessary to perform research on PWUD undergoing compulsory isolation in an Asian context. Finally, studying the joint effects of these variables is the key to understanding the basis of drug addiction and developing effective treatment methods as a next step. Even more important is determining the supportive psychological factors in PWUD to provide new ideas for helping such persons more successfully remain abstinent in the long term. We constructed a moderated mediation model (see Fig. 1). Therefore, we propose Hypothesis 1: The family intimacy of PWUD negatively predicts their relapse tendency; Hypothesis 2: The psychological capital of PWUD plays a mediating role in the relationship between family intimacy and relapse. Hypothesis 3: Self-efficacy plays a moderating role in the relationship between family intimacy and psychological capital.

\section{Methods \\ Participants}

Cluster random sampling method was used to select more than 1800 PWUD from a large drug rehabilitation center in Jiangxi Province, China from May to August 2020. First of all, PWUD has been divided into different groups in the drug rehabilitation center, it is generally divided into 20 groups according to the drug rehabilitation center. Secondly, a simple random method was adopted to select 10 groups out of 20 groups. Individuals with poor physical conditions and those who were difficult to participate in the rehabilitation center were excluded. All the individuals in the selected groups were included in the survey. A total of 880 PWUD were investigated. After eliminating 63 PWUD with incomplete answers, 817 valid questionnaires were left, with an effective response rate of $92.8 \%$.

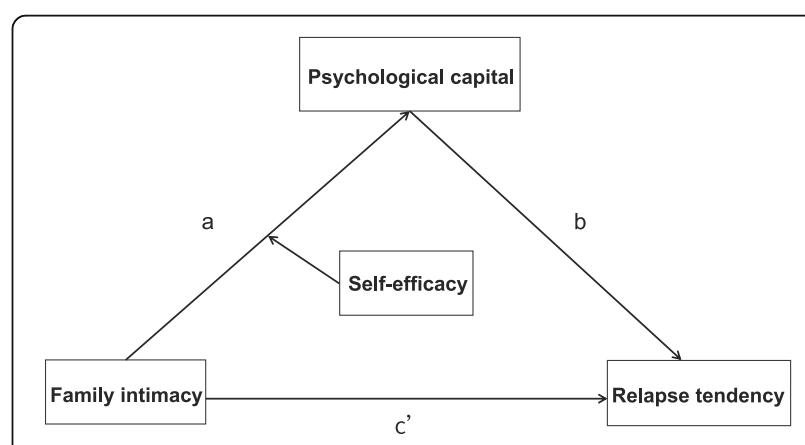

Fig. 1 A moderated mediating model 


\section{Measures}

\section{Demographic characteristics}

Background data were recorded for each participant, including age, educational level (elementary school or below, junior high school, senior high school or technical secondary school, junior college, undergraduate degree or above), marital status (unmarried, married, remarried, divorced or widowed), place of residence (urban areas, rural areas), and type of drug use (meth, ketamine, opium, heroin, others).

\section{Family intimacy and adaptability scale}

We used the Family Intimacy and Adaptability Scale [28]. The original scale consists of two scales measuring respondents' actual feelings about the current state of their family and the ideal family situation they would like to have, with 30 items each. The subscale of actual feelings about one's family situation includes two factors: intimacy and adaptability. Intimacy refers to the perceived emotional connection among family members (e.g., "Family members do their best to support each other when there are difficult times"). A 5-point scale was used ( $1=$ "not", 5 = "always"). Only participants' intimacy scores were counted in this study; higher scores indicated higher levels of family intimacy, and Cronbach's $\alpha$ was .89 in this study.

\section{General self-efficacy scale}

The General Self-Efficacy Scale is unidimensional [55], with a total of ten items (e.g., "I'm confident that I can cope effectively with anything that comes up unexpectedly") rated using a 4-point scale ( $1=$ "not correct", $4=$ "correct"). Higher scores indicate higher general selfefficacy, and Cronbach's $\alpha$ was .84 in this study.

\section{Relapse tendency questionnaire}

We used the Relapse Tendency Questionnaire [56], which has 18 items measuring the willingness to quit drugs ("I will encounter many difficulties and setbacks in the process of drug rehabilitation, and I am fully prepared for this"), substance substitution ("I hope to have the opportunity to enjoy drugs again and enjoy my addiction"), objective circumstances ("After I get clean, I want to move to a new place where no one knows me so that I can get rid of my drug friends and drugs completely"). The five dimensions were physical and mental condition ("physical condition after long-term drug use") and social support ("encouragement and support from family, relatives, and friends for me to quit drugs"). A 6point scale was used ( 0 indicating the least severe degree and 5 indicating the most severe degree), and a higher total score indicated a higher relapse tendency. Cronbach's $\alpha$ was .91 in this study.

\section{Positive psychological capital questionnaire}

We used the Positive Psychological Capital Questionnaire [57]. It assesses self-efficacy ("I am confident in my abilities"), resilience ("Bad experiences can depress me for a long time"), hope ("I am working hard to achieve my goals ") and optimism ("I tend to hang my head when things don't go my way") in four dimensions, with 26 entries in total, using a 7 -point scale $(1=$ "not at all consistent", 7 = "completely consistent"). Higher scores indicate higher levels of positive psychology in each dimension or overall. Cronbach's $\alpha$ was .87 in this study.

\section{Administration procedures}

The test was administered by a trained graduate student in psychology. Before the test, the tester read out the instructions and explained that the test was for scientific research only, that the questionnaire should be filled out according to the respondents' actual circumstances, that participants could withdraw or discontinue answering the questionnaire at any time, and that the confidentiality of the test results was guaranteed. All participants first signed the informed consent form and then completed the questionnaire. After completing the survey, each questionnaire was collected on-site, and participants received a gift worth $\$ 3$. The entire process was completed in a spacious, quiet, and air-conditioned classroom and lasted approximately $30 \mathrm{~min}$. All participants were tested by the rehabilitation hospital and were free of mental illness according to the DSM-IV criteria.

\section{Data analysis}

First, the common method deviation test was carried out. Using AMOS 24.0, family intimacy, self-efficacy, positive psychological capital, and relapse tendency were fixed as one factor, and the number of common factors was set as 1 for confirmatory factor analysis to check the model fit based on the hypothesis that "a single factor explains all the variation". Second, descriptive tests, difference analyses and correlation analyses were conducted on the results. SPSS 23.0 was used to conduct Spearman grade correlation for the four variables of family intimacy, self-efficacy, positive psychological capital and relapse tendency, and independent sample ttests and one-way analysis of variance (ANOVA) were used to test whether there were significant differences in relapse tendency among respondents with different demographic characteristics. Third, this study examined the mediating role of psychological capital between family intimacy and relapse tendency via mediation analysis [58]. In addition, we estimated the mediation proportion: how large a proportion of the total effect of family intimacy on relapse tendency is mediated through psychological capital. The algorithm used was: mediation proportion $=(\mathrm{ab}) / \mathrm{c}[59,60]$. Fourth, this study examined 
whether the first half of the mediation process was moderated by self-efficacy. Moderated mediation is often used to test whether the size of the mediation effect depends on the value of the moderating variable [61]. Moderated mediation analysis was carried out using Hayes's process macro (Model 7). In addition, the bootstrap method was used to test the significance of all effects to obtain the standard error of parameter estimation [62]. The bootstrap method generates $95 \%$ bias-corrected confidence intervals for these effects from 5000 resampled datapoints, and confidence intervals that do not include zero indicate significant influence.

\section{Results}

\section{Common method bias}

Because this study used self-reporting methods to collect data, common method bias may exist. To reduce the impact of common method bias on the study results, we used procedural controls and statistical method test controls. For the procedural control, we adopted a questionnaire design with a randomized order of questions, and for the statistical control, we tested the common method bias by structural equation modelling using a common factor of 1 for the validation factor analysis to test the hypothesis that "a single factor explains all the variation" more precisely [63]. Using Amos 24.0, family intimacy, self-efficacy, positive psychological capital, and relapse tendency were fixed as one factor to check the model fit: $\chi^{2}=30,060.969(p<0.001), d f=3486, \chi^{2} / d f=8.623, C F I=$ $0.000, T L I=0.000, R M S E A=0.097, S R M R=0.166$. The model fit was poor, indicating that there was no serious common method bias in this study.

\section{Descriptive statistical analysis}

Table 1 shows the sociodemographic characteristics. A total of 817 participants were included in the study. The participants' ranged in age from 17 to 62 years, with a mean age of $34.45 \pm 8.28$ years.

\section{Differences in relapse tendency among groups differing by marital status, education level, and type of drug used} To investigate whether there were differences in relapse tendency by age, marital status, education level, place of residence, and type of drug used, these variables were used as grouping variables, and independent sample ttests or one-way ANOVA was conducted. The results are shown in Table 2. The LSD post hoc test showed that PWUD who were "remarried" $(32.12 \pm 16.04)$ were more likely to relapse than those who were "unmarried"(27.45 \pm 13.06$)$, “married" $(25.72 \pm 15.01)$ and "divorced or widowed" $(26,94 \pm 14.20)$. PWUD with " elementary school or below" $(31.02 \pm 15.97)$ score higher than those with "junior high school"(25.98 \pm 13.77$)$, " senior high school or technical secondary school " $(26.05 \pm$ 13.67); PWUD who used "heroin"(31.01 \pm 14.18$)$ and "other drugs" $(35.30 \pm 18.74)$ scored higher than those who used "meth" $(26.13 \pm 14.03)$ and "ketamine" $(26.38 \pm$ 13.64). Age $(F=1.16, p>0.05)$ and place of residence $(F=0.44, p>0.05)$ were not associated with statistically significant differences in relapse tendency, and the results are shown in Table 2.

\section{Descriptive statistics and correlation analysis}

Table 3 lists the mean, standard deviation and correlation analysis results for each variable. Compared with

Table 1 Characteristics of PWUD $(N=817)$

\begin{tabular}{|c|c|c|c|}
\hline Variables & & $N$ & Percent \\
\hline \multirow[t]{5}{*}{ Educational level } & elementary school or below & 131 & 16.0 \\
\hline & junior high school & 466 & 57.0 \\
\hline & senior high school or technical secondary school & 188 & 23.0 \\
\hline & junior college & 23 & 2.9 \\
\hline & undergraduate degree or above & 9 & 1.1 \\
\hline \multirow[t]{4}{*}{ Marital status } & unmarried & 273 & 33.4 \\
\hline & married & 306 & 37.5 \\
\hline & remarried & 32 & 3.9 \\
\hline & divorced or widowed & 206 & 25.2 \\
\hline \multirow[t]{2}{*}{ Place of residence } & urban areas & 496 & 60.7 \\
\hline & rural areas & 321 & 39.3 \\
\hline \multirow[t]{5}{*}{ Types of drug use } & meth & 609 & 74.5 \\
\hline & ketamine & 105 & 12.9 \\
\hline & opium & 2 & 0.2 \\
\hline & heroin & 83 & 10.2 \\
\hline & other & 18 & 2.2 \\
\hline
\end{tabular}


Table 2 Marital status, educational level, and types of drug use differ in relapse tendency

\begin{tabular}{|c|c|c|c|c|c|}
\hline & & Sum of Squares & Mean square & $F$ & $p$ \\
\hline \multirow[t]{3}{*}{ Marital status } & Among groups & 2275.53 & 568.88 & 2.85 & 0.023 \\
\hline & Within-group & $162,276.09$ & 199.85 & & \\
\hline & Total & $164,551.62$ & & & \\
\hline \multirow[t]{3}{*}{ Educational level } & Among groups & 3223.394 & 644.68 & 3.24 & 0.007 \\
\hline & Within-group & $161,328.22$ & 198.93 & & \\
\hline & Total & $164,551.62$ & & & \\
\hline \multirow[t]{3}{*}{ Types of drug use } & Among groups & 3638.20 & 727.64 & 3.67 & 0.003 \\
\hline & Within-group & $160,913.42$ & 198.41 & & \\
\hline & Total & $164,551.62$ & & & \\
\hline
\end{tabular}

the Chinese norm $(63.9 \pm 8.0)$, the family intimacy score of PWUD $(62.35 \pm 10.64)$ was low $(p<0.01)$. The results of the correlation analysis showed that family intimacy, psychological capital and self-efficacy were significantly negatively correlated with relapse tendency. There was a significant positive correlation between family intimacy, psychological capital and self-efficacy and a significant positive correlation between family intimacy and psychological capital.

\section{The relationship between family intimacy and relapse tendency: a moderated mediation model test}

First, relapse behaviour differed significantly by participants' marital status, education level, and type of drug use. Therefore, the mediating effect of psychological capital on the relationship between family intimacy and relapse tendency was tested using Model 4 (Model 4 is a simple mediation model) in the SPSS macro developed by Hayes [62], controlling for the variables of marital status, education level, and type of drug use. The results (see Table 4) showed that the negative predictive effect of family intimacy on relapse tendency was significant $(\beta=-0.19, t=-4.13, p<0.001 ;$ " $\beta$ " is the standardized coefficient), but when the mediating variable was entered, the predictive effect of family intimacy on relapse tendency was not significant $(\beta=-0.07, t=-1.44, p>$ $0.05)$. Therefore, Hypothesis 1 was verified. The positive predictive effect of family intimacy on psychological capital was significant $(\beta=0.02, t=10.79, p<0.001)$, as was

Table 3 Means, Standard Deviations (SD), and Correlations of all variables

\begin{tabular}{lllllll}
\hline & $\mathbf{M}$ & $\mathbf{S D}$ & $\mathbf{1}$ & $\mathbf{2}$ & $\mathbf{3}$ & $\mathbf{4}$ \\
\hline 1.Family intimacy & 62.35 & 10.64 & 1.00 & & & \\
2.General self-efficacy & 2.47 & 0.55 & $.244^{* *}$ & 1.00 & & \\
3.Relapse tendency & 26.85 & 14.20 & $-.150^{* *}$ & $-.155^{* *}$ & 1.00 & \\
4.Psychological capital & 4.46 & 0.74 & $.367^{* *}$ & $.479^{* *}$ & $-.285^{* *}$ & 1.00 \\
\hline${ }^{* *} p<0.01$ & & & & & &
\end{tabular}

the negative predictive effect of psychological capital on relapse tendency $(\beta=-5.01, t=-7.17, p<0.001)$.

The 95\% bootstrap confidence interval for the direct effect of family intimacy on relapse tendency and the mediating effect of psychologi

cal capital did not contain 0 (see Table 5), indicating that family intimacy not only directly predicted relapse tendency but also predicted relapse behaviour through the mediating effect of psychological capital; thus, Hypothesis 2 was verified. This direct effect $(-0.07)$ and mediating effect $(-0.10)$ accounted for 41.18 and $58.82 \%$ of the total effect $(-0.17)$, respectively.

Second, the moderated mediation model was tested using Model 7 of the SPSS macro developed by Hayes (Model 7 assumes that the first half of the mediation model and the direct path are moderated, consistent with the theoretical model of this study), controlling for the variables of marital status, education level, and type of drug use. The results showed (see Table 6) that there was a significant effect of family intimacy on psychological capital after general self-efficacy was entered into the model $(\beta=0.02, t=8.62, p<0.001)$, and the product term of family intimacy and general self-efficacy was a significant predictor of psychological capital $(\beta=0.01$, $t=2.97, p<0.001$ ), indicating that general self-efficacy was able to moderate the predictive effect of family intimacy on psychological capital. The detailed path model is shown in Fig. 2.

To understand the nature of the interaction effect between family intimacy and self-efficacy, participants with different levels of self-efficacy were analysed separately, and the mediated effect values and $95 \%$ bootstrap confidence intervals for psychological capital between family intimacy and relapse tendency for both groups of participants are shown in Table 7 ("Slope" in the table is a standardized slope estimate). Further simple slope analysis showed (see Fig. 3) that for participants with higher levels of self-efficacy $(M+1 S D)$, family intimacy had a significant positive predictive effect on psychological capital (simple slope $=0.023, t=8.32, p<0.001$ ), 
Table 4 The mediation model test of psychological capital

\begin{tabular}{|c|c|c|c|c|c|}
\hline Outcome variables & Independence variables & $R^{2}$ & $F$ & $\beta$ & $t$ \\
\hline \multirow[t]{5}{*}{ Relapse tendency } & & 0.04 & $9.12^{* * *}$ & & \\
\hline & Marital status & & & 0.13 & 0.31 \\
\hline & educational level & & & -1.22 & -1.85 \\
\hline & types of drug use & & & 1.31 & $3.70^{* * *}$ \\
\hline & Family intimacy & & & -0.19 & $-4.13^{* * *}$ \\
\hline \multirow[t]{5}{*}{ Psychological capital } & & 0.16 & $38.44^{* * *}$ & & \\
\hline & Marital status & & & -0.002 & -0.11 \\
\hline & educational level & & & 0.16 & $4.86^{* * *}$ \\
\hline & types of drug use & & & -0.005 & -0.26 \\
\hline & Family intimacy & & & 0.02 & $10.79^{* * *}$ \\
\hline \multirow[t]{6}{*}{ Relapse tendency } & & 0.10 & $18.02^{* * *}$ & & \\
\hline & Marital status & & & 0.12 & 0.29 \\
\hline & educational level & & & -0.44 & -0.68 \\
\hline & types of drug use & & & 1.29 & $3.75^{* * *}$ \\
\hline & Family intimacy & & & -0.07 & -1.44 \\
\hline & Psychological capital & & & -5.01 & $-7.17^{* * *}$ \\
\hline
\end{tabular}

whereas for participants with lower levels of self-efficacy $(M-1 S D)$, family intimacy also had a positive predictive effect on psychological capital (simple slope $=0$. 013, $t=$ $4.78, p<0$. 001). The predictive effect was small, indicating that the predictive effect of family intimacy on psychological capital gradually increased as the level of selfefficacy increased (see Table 6). Therefore, Hypothesis 3 was verified.

\section{Discussion}

The relationship between family intimacy and relapse tendency in PWUD

In this study, although there is a small correlation between family intimacy and relapse tendency, family intimacy was still a negative predictor of relapse tendency, which is consistent with previous studies [12]. From the point of view of PWUD, during the COVID-19 pandemic, due to the necessity of implementing prevention measures to mitigate disease transmission, drug rehabilitation centres temporarily forbade visits, communication between PWUD and their families was temporarily blocked, and the emotional connection with family was weakened [64],these may be different from other studies showing a high negative correlation between family intimacy and relapse tendency [13]. In addition, the traditional service industry and manufacturing industry are under great threat [65], and there have been layoffs, wage arrears, bankruptcy and other phenomena that have aggravated the psychological distress of PWUD with respect to the economic situation of their families [66], making them prone to negative emotions. Moreover, compared to people in individualistic cultures, Chinese people, who live in a collectivist culture, are more introverted, and most individuals are reluctant to express their emotions openly and tell their loved ones about stressful events; instead, they generally choose to hide their emotions [3]. On the other hand, drug use is a crime in China, and it is often not tolerated even within the family; families may minimize mention of and avoid talking about the PWUD due to the traditional culture of "not washing your dirty linen in public" [67]. This reduces the PWUD's feelings of emotional closeness to the family, i.e., the individual does not have positive experiences of emotional connection with the family, which also explains the low family intimacy scores. From the point of view of the families of PWUD, because recovering PWUD have to deal with the multiple pressures as they readjust and reintegrate into social life after leaving

Table 5 Mediating effect analysis of psychological capital

\begin{tabular}{lllll}
\hline & Standardization effect estimation & Relative effect value & The Boot Standard Error (SE) & 95\% Confidence interval (Cl) \\
\hline The total effect $\left(a b+c^{\prime}\right)$ & $-0.10+(-0.07)=-0.17$ & $100 \%$ & 0.05 & $-0.28,-0.10$ \\
Direct effect $\left(c^{\prime}\right)$ & -0.07 & $41.18 \%$ & 0.05 & $-0.16,0.03$ \\
Mediating effect $(a b)$ & $0.02 \times(-5.01)=-0.10$ & $58.82 \%$ & 0.02 & $-0.17,-0.08$ \\
\hline
\end{tabular}


Table 6 Moderated mediation model testing

\begin{tabular}{|c|c|c|c|c|c|}
\hline Outcome variables & Independence variables & $R^{2}$ & $F$ & $\beta$ & $t$ \\
\hline \multirow[t]{7}{*}{ Psychological capital } & & 0.32 & $62.81^{* * *}$ & & \\
\hline & Marital status & & & 0.01 & 0.33 \\
\hline & educational level & & & 0.12 & $3.98^{* * *}$ \\
\hline & types of drug use & & & 0.01 & 0.70 \\
\hline & Family intimacy & & & 0.02 & $8.62^{* * *}$ \\
\hline & General self-efficacy & & & 0.53 & $13.21^{* * *}$ \\
\hline & Family intimacy $\times$ General self-efficacy & & & 0.01 & $2.97^{* * *}$ \\
\hline \multirow[t]{6}{*}{ Relapse tendency } & & 0.10 & 18.02 & & \\
\hline & Marital status & & & 0.12 & 0.29 \\
\hline & educational level & & & -0.44 & -0.68 \\
\hline & types of drug use & & & 1.29 & $3.75^{* * *}$ \\
\hline & Family intimacy & & & -0.07 & -1.44 \\
\hline & Psychological capital & & & -5.01 & $-7.17^{* * *}$ \\
\hline
\end{tabular}

rehab, if PWUD do not receive emotional support and respect from family members, instead experience poorer family intimacy due to stigmatization [31], which may lead to relapse behaviour [68]. Indeed, family members with low family intimacy are more likely to experience negative emotions due to poor communication, increase family conflict, and create a violent or indifferent family atmosphere [69], failing to encourage positive emotions in the recovering PWUD or even to properly guide the PWUD to a hopeful life and enhance ability to recover quickly from adversity [21]. The average age of the participants in this study was $34.41 \pm 8.01$ years, which is the age at which Chinese begin to formally assume more responsibilities in their families of origin and nuclear families and at work, but the participants current drug use behaviours do not match the roles and responsibilities they should be assuming. Self-difference theory [70] suggests that there may be a discrepancy between an individual's "real self" and "ought self". That is, an individual may believe that his current drug-taking behaviour is inconsistent with the behaviours that important others (such as parents, children, and lovers) think an

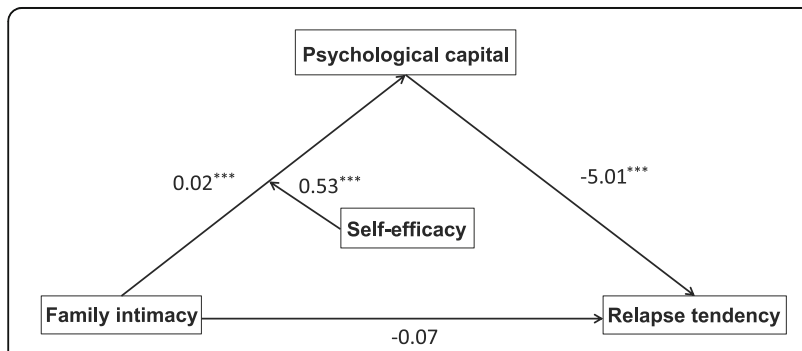

Fig. 2 Path coefficients of family intimacy, self-efficacy, pyschological capital and relapse tendency. ${ }^{* *} p<0.001$ individual should engage in to fulfil his responsibilities and obligations, and this difference leads to the generation of negative emotions. The negative reinforcement emotion processing model [71] suggests that avoidance of negative emotions is the preferred motivation for individuals to maintain addictive behaviours and that PWUD may resort to additional substance abuse behaviours to avoid negative emotions, which may further trigger relapse behaviours. Therefore, in China, the family members of PWUD should be encouraged to cooperate with each other and with the rehabilitation centre and participate in the rehabilitation process. In terms of communication skills, in special cases, the drug rehabilitation centre should take advantage of existing technology, such as "cloud" communication, to enhance the emotional connection between family members and PWUD.

\section{Analysis of the mediating role of psychological capital in the relationship between family intimacy and relapse tendency}

This study found that psychological capital played a mediating role in the relationship between family intimacy and relapse tendency. This is consistent with previous studies [72]. Good communication and strong emotional

Table 7 The mediating effect of psychological capital on different levels of self-efficacy

\begin{tabular}{lllll}
\hline Self-efficacy level & Slope & Bootstrap Standard Error & LLCI & ULCI \\
\hline$M-1 S D$ & -0.06 & 0.02 & -0.10 & -0.03 \\
$M \pm 1 S D$ & -0.09 & 0.02 & -0.13 & -0.06 \\
$M+1 S D$ & -0.12 & 0.02 & -0.17 & -0.07 \\
\hline
\end{tabular}

"Slope"is a standardized slope estimate 


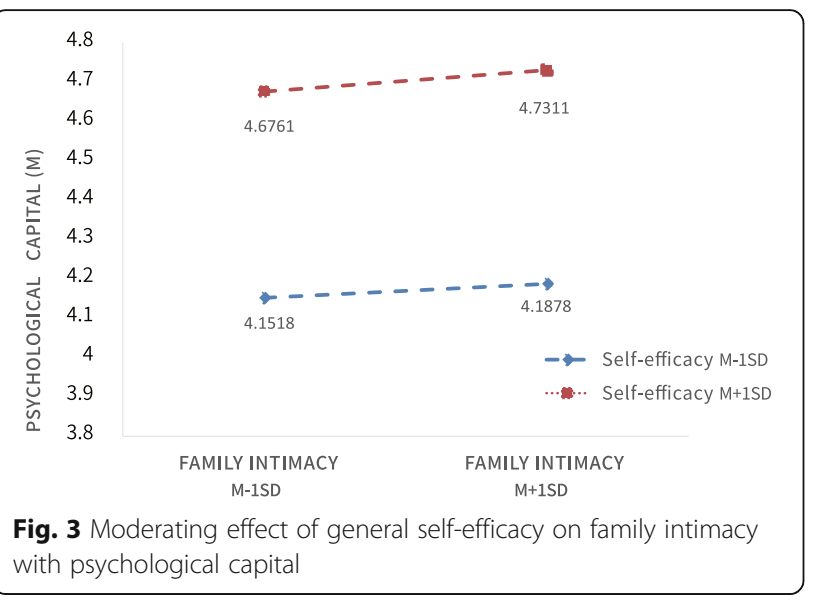

ties among family members are predictors of the development of positive qualities such as optimism and selfefficacy [29], whereas family conflict and low levels of family intimacy predispose individuals to problems such as pessimism and difficulties with social adjustment [73] and a lack of good coping strategies. High levels of psychological capital are strongly associated with less substance abuse and relapse behaviour [74], and the Hope Therapy educational intervention study showed that positive psychotherapy was effective in reducing depression and predicting relapse in people who sought addiction treatment [75]. Conversely, individuals with less psychological capital are more impulsive, helpless, and prone to reliance on substance-abusing behaviours to regulate their emotions and escape stress, making PWUD prone to relapse [34].

Triadic reciprocal determinism (TRD) [76] states that individuals' subjective factors, the environment they live in, and the behaviours they exhibit are interactively determined. That is, the emergence of relapse behaviours in recovering PWUD is influenced not only by the family environment but also by their traits such as their beliefs, cognition, and psychological capital [10]. Thus, even when recovering PWUD feel the same level of family emotional connection, differences in psychological capital can influence hope and optimism about future lives, PWUD's belief that they can quit drugs, and their ability to make behavioural choices related to substance abuse. However, it has also been shown that levels of psychological capital are influenced by family [72]. PWUD who perceive good family emotional connections have higher self-confidence and positive optimism and possess the determination and hope to rebuild their lives and reform, and receiving emotional support from family enables individuals to recover quickly from difficult situations and reduce use of drugs to de-stress. When a recovering PWUD perceives poor emotional relationships among family members, on the one hand, the individual is affected by stigmatization, and the indifferent and poor attitudes of family members make the individual believe that everyone rejects him or her. On the other hand, the family is the most important and influential source of social support for the individual, but the recovering PWUD does not receive emotional support from family. This can lead to a loss of hope in life and confidence in recovery, making it difficult to resolve negative emotions and eventually leading to reengagement in drug use [77]. Therefore, psychological capital also contributes to the reduction of relapse tendencies, and rehabilitation centres can conduct group counselling activities that enhance positive psychological qualities such as optimism, self-efficacy, resilience, and hope, which can help PWUD recover quickly and positively from imbalances caused by stressful events and reduce substance abuse cravings and relapse behaviours [78].

\section{Analysis of the moderating role of self-efficacy}

The results of this study indicate that the effect of family intimacy on the psychological capital of PWUD is moderated by self-efficacy, and there are differences in the effect of family intimacy on psychological capital at different levels of self-efficacy. When the level of selfefficacy of PWUD is low, the predictive effect of family intimacy on psychological capital is small; conversely, when the level of self-efficacy of PWUD is high, the predictive effect of family intimacy on psychological capital is large. This result is consistent with previous studies on the protective role of self-efficacy [79]. Fergus and Zimmerman [80] proposed that the protective factors that prevent negative effects may be positive factors internal to the individual (e.g., competence, coping skills, and self-efficacy) or positive factors external to the individual (e.g., parental support, adult guidance). The protective-stability model [15] proposes that protective factors help to counteract the effects of risk, with higher levels of risk being associated with higher levels of negative outcomes when protective factors are absent but no relationship between risk and outcome existing when protective factors are present. That is, both family intimacy and self-efficacy are protective factors that can have a reinforcing effect on the improvement of psychological capital levels, i.e., high levels of self-efficacy can both promote higher levels of psychological capital in recovering PWUD who have good family intimacy and mitigate the negative effects of low family intimacy and improve psychological capital levels. Low family intimacy means that recovering PWUD have difficulty obtaining effective emotional support from their families and do not perceive close emotional connections among family members; thus, the negative emotions cannot be confided in their families in a timely manner, which can trigger 
negative psychological emotions such as anxiety and depression, leading to a decrease in forms of psychological capital such as optimism and hope [81]. Conversely, PWUD with high self-efficacy have more strategies to mitigate and cope with the effects of various negative emotions (such as cognitive reappraisal) [82], and PWUD can buffer the negative effects of family conflict, use positive reframing strategies to cope with challenges, focus on the optimistic aspects of the situation, and quickly recover from failure and be hopeful about new goals for the future [8]. Therefore, rehabilitation centres should carry out physical rehabilitation training, such as Qigong, Taijiquan, yoga, and free rotation aerobic exercise [83]. From the perspective of external intervention, the symptoms of depression and negative emotions caused by decreased dopamine release can be reduced to improve the success rate of withdrawal and reduce drug craving and relapse. Embodied cognition theory suggests that cognitive processes are influenced by both the body and the environment and that there is a strong link between physical experiences and psychological states [84]. When the body is restored, individuals can feel positive and happy emotions, which can improve their selfconfidence and self-efficacy.

\section{Limitations}

The following limitations and shortcomings remain in this study. First, this study used a cross-sectional design, and although we adopted procedural and statistical controls to minimize the effects of common method bias, as with all cross-sectional studies, a longitudinal study is still needed to determine the causal relationships among the variables. Second, the COVID-19 epidemic has affected the psychological stress response and psychological well-being of individuals and family members, which can lead to abnormal behaviours related to drug used [85]. This study examined the relationship between family intimacy and relapse tendency in PWUD only during the COVID-19 outbreak. For this reason, subsequent studies should consider comparing the relationship between family intimacy and relapse tendency in PWUD found herein with that in nonspecial periods to confirm the influence of the unique family conditions created by the COVID-19 pandemic on relapse tendency. Third, this study used questionnaire method, which may have self-report bias. In the follow-up study, in addition to self-assessment, other assessment (for example: family, rehabilitation centers staff) and interview method will be added to make the research results more objective. Fourth, the participants of this study were from male who use drugs in compulsory rehabilitation centers of China. Due to the violation of social order and legal system, the public has generated wrong ideas and negative stereotypes about PWUD. As a result, it is difficult for PWUD to integrate into the society. Therefore, the applicability of this result to voluntary PWUD and female PWUD should be cautious. Finally, according to Chinese law, PWUD needs to take different measures for drug rehabilitation, such as compulsory drug rehabilitation center, community drug rehabilitation, etc., so our findings do not apply to in other societies people who voluntarily stopping drugs or who have a shared history of drug use by family members.

\section{Conclusion}

This study drew the following conclusions: (1) the average family intimacy score of PWUD was low; (2) family intimacy negatively predicted the relapse tendency of PWUD; (3) psychological capital mediated the relationship between family intimacy and relapse tendency; (4) the indirect effect of family intimacy on relapse tendency was moderated by self-efficacy in the first half of the mediation. Compared with PWUD with low self-efficacy, PWUD with high self-efficacy had more psychological capital. Therefore, there are both mediating and moderating effects between family intimacy and relapse tendency. The results of this study suggest that family members of PWUD and rehabilitation centres should be encouraged to participate in the rehabilitation process of PWUD, improve the communication skills of family members and improve the psychological capital level of PWUD to reduce the possibility of relapse tendency.

\section{Abbreviations \\ PWUD: people who use drugs; SD: Standard Deviation; SE: Standard Error; $\mathrm{Cl}$ : Confidence Interval \\ Acknowledgements \\ The authors wish to thank participants and staff in Jiangxi compulsory drug rehabilitation center.}

\section{Authors' contributions}

Zeng, Xiaoqing: Conceptualization, Methodology, Data Collection, Visualization. Writing-original draft, reviewing, and editing; Lu, Mengyao: Software, Writing-original draft, reviewing, editing and submission; Chen, Meirong, Writing - original draft, reviewing, and editing.

\section{Funding}

This work was supported by the National Social Science Foundation of China (grant numbers 19BGL230), and the "13th Five-Year Plan" Project of Educational Science in Jiangxi Province (grant numbers 20YB19).

\section{Availability of data and materials \\ The raw data supporting these findings can be found in the supplementary} file.

\section{Declarations}

Ethics approval and consent to participate

This study was approved by the Drug rehabilitation Administration of Jiangxi Province, China, and approved by the Ethics Committee of Psychology College of Jiangxi Normal University. All participants were asked to obtain the informed consent form in written. All respondents answer was kept confidential. 


\section{Consent for publication}

Not applicable.

\section{Competing interests}

The authors declare no conflicts of interest.

\section{Author details}

'School of Psychology, Institute of Psychology, Jiangxi Normal University, Nanchang, China. ${ }^{2}$ Department of Education, Nanchang Normal University, Nanchang, China.

\section{Accepted: 28 May 2021}

\section{Published online: 08 June 2021}

\section{References}

1. World Drug Report 2020: 35 Million People Addicted to Drugs. 2020, June 25. Retrieved September 19, 2020; Available from: https://news.un.org/zh/ story/2020/06/1060732

2. Kabbani N, Olds JL. Does COVID19 infect the brain? If so, smokers might be at a higher risk. Mol Pharmacol. 2020;97(5):351-3. https://doi.org/10.1124/ molpharm.120.000014.

3. Chen M, Zeng X, Chen Y. Self-concept and abstinence motivation in male drug addicts: coping style as a mediator. Soc Behav Personal Int J. 2020; 48(7):1-15.

4. Zeng X, Chen Y. Associations of deviant peer affiliation with youths' substance use disorder abstention motivation: the mediating role of perceived social support and the moderating role of collective identity. J Ethn Subst Abus. 2020:1-23. https://doi.org/10.1080/15332640.2020.1777608.

5. Zeng $X, \operatorname{Tan} C$. The relationship between the family functioning of individuals with drug addiction and relapse tendency: a moderated mediation model. Int J Environ Res Public Health. 2021;18(2):625. https://doi. org/10.3390/ijerph18020625.

6. Kwok SYCL, Cheng L, Wong DFK. Family emotional support, positive psychological capital and job satisfaction among Chinese white-collar workers. J Happiness Stud. 2015;16(3):561-82. https://doi.org/10.1007/s1 0902-014-9522-7.

7. Fossati A, Somma A. Improving family functioning to (hopefully) improve treatment efficacy of borderline personality disorder: an opportunity not to dismiss. Psychopathology. 2018;51(2).

8. Kliewer W, Murrelle L, Prom E, Ramirez M, Obando P, Sandi L, et al. Violence exposure and drug use in central American youth: family cohesion and parental monitoring as protective factors. J Res Adolesc. 2006;16(3):455-78. https://doi.org/10.1111/j.1532-7795.2006.00502.x.

9. Molero Jurado MDM, Pérez-Fuentes MC, Barragán Martín AB, del Pino Salvador RM, Gázquez Linares JJ. Analysis of the relationship between emotional intelligence, resilience, and family functioning in adolescents' sustainable use of alcohol and tobacco. Sustainability. 2019;11(10):2954. https://doi.org/10.3390/su11102954

10. Azmi AA, Hussin H, Ishak SID, Daud@Fhiri NS. Drug addicts: psychosocial factor contributing to relapse. MATEC Web of Conferences. 2018;150(6): 05097. https://doi.org/10.1051/matecconf/201815005097.

11. Olson DH. Circumplex model of marital and family systems. J Fam Ther. 2000;22(2):144-67. https://doi.org/10.1111/1467-6427.00144.

12. Marsiglia FF, Kulis S, Parsai M, Villar P, Garcia C. Cohesion and conflict: family influences on adolescent alcohol use in immigrant Latino families. J Ethn Subst Abus. 2009;8(4):400-12. https://doi.org/10.1080/15332640903327526.

13. Costantini MF, Wermuth L, Sorensen JL, Lyons JS. Family functioning as a predictor of progress in substance abuse treatment. J Subst Abus Treat. 1992;9(4):331-5. https://doi.org/10.1016/0740-5472(92)90027-L.

14. Vega WA, Sribney W. Parental risk factors and social assimilation in alcohol dependence of Mexican Americans. J Stud Alcohol. 2003;64(2):167-75. https://doi.org/10.15288/jsa.2003.64.167.

15. Luthar SS, Cicchetti D, Becker B. The construct of resilience: a critical evaluation and guidelines for future work. Child Dev. 2000;71(3):543-62. https://doi.org/10.1111/1467-8624.00164.

16. Wu S, Zheng $X$. The effect of family adaptation and cohesion on the wellbeing of married women: a multiple mediation effect. J Gen Psychol. 2020; 147(1):90-107. https://doi.org/10.1080/00221309.2019.1635075.

17. Broman CL, Reckase MD, Freedman-Doan CR. The role of parenting in drug use among black, Latino and white adolescents. J Ethn Subst Abus. 2006; 5(1):39-50. https://doi.org/10.1300/J233v05n01_03.
18. Rajesh V, Diamond PM, Spitz MR, Wilkinson AV. Smoking initiation among Mexican heritage youth and the roles of family cohesion and conflict. J Adolesc Health. 2015;57(1):24-30. https://doi.org/10.1016/j.jadohealth.2015. 01.021 .

19. Lakey B, Cohen S. Social support: theory. Measurement and Intervention. 2000:29-52.

20. Dary. Family Support and Family Function of Mothers who Have A Child with Down Syndrome. in International Nursing Conference: Continuous Quality Improvement in Nursing Education toward Quality in Nursing Care and Services in the Era of ASEAN Economic Community. 2016.

21. Tesfai AH. Alcohol and substance abuse among students at University of KwaZulu-Natal, South Africa: the protective role of psychological capital and health promoting lifestyle. 2016.

22. Johnson VI The effects of intimate relationship education on relationship optimism and attitudes toward marriage. 2009.

23. Gujar NM, Ali A. Effects of psychological capital and self-esteem on emotional and behavioral problems among adolescents. J Ment Health Hum Behav. 2019;24:85.

24. Luthans F, Luthans KW, Luthans BC. Positive psychological capital: beyond human and social capital. Business Horizons. 2004;47(1):45-50. https://doi. org/10.1016/j.bushor.2003.11.007.

25. Stubbs NS, Maynard D-MB. Academic self-efficacy, school engagement and family functioning, among postsecondary students in the Caribbean. J Child Fam Stud. 2017;26(3):792-9. https://doi.org/10.1007/s10826-016-0595-2.

26. Lu C, Yuan L, Lin W, Zhou Y, Pan S. Depression and resilience mediates the effect of family function on quality of life of the elderly. Arch Gerontol Geriatr. 2017;71:34-42. https://doi.org/10.1016/j.archger.2017.02.011.

27. Miller IW, et al. The McMaster approach to families: theory, assessment, treatment and research. J Fam Ther. 2010;22(2):168-89.

28. Olson DH, Sprenkle DH, Russell CS. Circumplex model of marital and family systems: I. cohesion and adaptability dimensions, family types, and clinical applications. Fam Process. 1979;18(1):3-28. https://doi.org/10.1111/j.1545-53 00.1979.00003.x.

29. Dunkel CS et al. Family cohesion and the general factor of personality: examining differences in monozygotic twin pairs. Evolutionary Psychological Science, 2018.

30. Park YY, Jeong YJ, Lee J, Moon N, Bang I, Kim H, et al. The influence of family adaptability and cohesion on anxiety and depression of terminally ill cancer patients. Support Care Cancer. 2018;26(1):313-21. https://doi.org/10.1 007/s00520-017-3912-4.

31. You YH, et al. Predictors of five-year relapse rates of youths with substance abuse who underwent a family-oriented therapy program. Ann General Psychiatry. 2020:19(1).

32. Sun R, Ren Y, Li X, Jiang Y, Liu S, You J. Self-compassion and family cohesion moderate the association between suicide ideation and suicide attempts in Chinese adolescents. J Adolesc. 2020;79:103-11. https://doi. org/10.1016/j.adolescence.2019.12.010.

33. Stratman JL, Youssef-Morgan CM. Can positivity promote safety? Psychological capital development combats cynicism and unsafe behavior. Saf Sci. 2019;116:13-25. https://doi.org/10.1016/j.ssci.2019.02.031.

34. Franken IHA, Hendriks VM, Haffmans PMJ, van der Meer CW. Coping style of substance-abuse patients: effects of anxiety and mood disorders on coping change. J Clin Psychol. 2001;57(3):299-306. https://doi.org/10.1002/jclp.1013.

35. Fredrickson BL. What good are positive emotions? Rev Gen Psychol. 1998; 2(3):300-19. https://doi.org/10.1037/1089-2680.2.3.300.

36. Abbas M, Raja U. Impact of psychological capital on innovative performance and job stress. Canadian Journal of Administrative Sciences/Revue Canadienne des Sciences de l'Administration. 2015;32(2):128-38. https://doi. org/10.1002/cjas.1314.

37. Bagheri M, Tagvaei D. Investigation of relationship between addictive substances abuse and psychological hardiness, quality of life, and selfconcept in addicts. Qom University of Medical Sciences Journal. 2017;11(3): 50-6.

38. Majewska MD, Gordon HW, Thadani P. Stress and drug abuse. Psychoneuroendocrinology. 2002;27(1):1-3. https://doi.org/10.1016/S0306-4 530(01)00032-4

39. Major B, Cozzarelli C, Sciacchitano AM, Cooper ML, Testa M, Mueller PM. Perceived social support, self-efficacy, and adjustment to abortion. J Pers Soc Psychol. 1990;59(3):452-63. https://doi.org/10.1037/0022-3514.59.3.452.

40. Ebstrup JF, Eplov LF, Pisinger C, Jørgensen T. Association between the five factor personality traits and perceived stress: is the effect mediated by 
general self-efficacy? Anxiety Stress Coping. 2011;24(4):407-19. https://doi. org/10.1080/10615806.2010.540012.

41. Bandura A. Self-efficacy: toward a unifying theory of behavioral change. Psychol Rev. 1977;84(2):191-215. https://doi.org/10.1037/0033-295X.84.2.191.

42. Schunk DH. Self-efficacy and academic motivation. Educ Psychol. 1991;26(34):207-31. https://doi.org/10.1207/s15326985ep2603\&4_2

43. Karademas EC. Self-efficacy, social support and well-being: the mediating role of optimism. Personal Individ Differ. 2006;40(6):1281-90. https://doi. org/10.1016/j.paid.2005.10.019.

44. Tehranineshat B, Mohammadi F, Mehdizade Tazangi R, Sohrabpour M, Parviniannasab AM, Bijani M. A study of the relationship among burned patients' resilience and self-efficacy and their quality of life. Patient Prefer Adherence. 2020;14:1361-9. https://doi.org/10.2147/PPA.S262571.

45. Mesurado B, Vidal EM, Mestre AL. Negative emotions and behaviour: the role of regulatory emotional self-efficacy. J Adolesc. 2018;64:62-71. https:// doi.org/10.1016/j.adolescence.2018.01.007.

46. Parto M. Problem solving, self-efficacy, and mental health in adolescents: assessing the mediating role of assertiveness. Procedia Soc Behav Sci. 2011; 30:644-8. https://doi.org/10.1016/j.sbspro.2011.10.125.

47. Schönfeld P, Brailovskaia J, Bieda A, Zhang XC, Margraf J. The effects of daily stress on positive and negative mental health: mediation through selfefficacy. Int J Clin Health Psychol. 2016;16(1):1-10. https://doi.org/10.1016/j. ijchp.2015.08.005.

48. Pellegrino P. Does alcoholics anonymous participation decrease learned helplessness and increase self-efficacy? PCOM Psychology Dissertations. 2009;113.

49. Mohebi Nooredinvand MH, Shehni Yeilagh M, Sharifi HP. The relationship of psychological capital (hope, optimism, resiliency and self-efficacy) with the achievement goals and academic performance of the first-year students. 2014.

50. Kadden RM, Litt MD. The role of self-efficacy in the treatment of substance use disorders. Addict Behav. 2011;36(12):1120-6. https://doi.org/10.1016/j.a ddbeh.2011.07.032.

51. Victor SE, Hipwell AE, Stepp SD, Scott LN. Parent and peer relationships as longitudinal predictors of adolescent non-suicidal self-injury onset. Child Adolesc Psychiatry Ment Health. 2019;13(1):1-13. https://doi.org/10.1186/s13 034-018-0261-0.

52. Mattanah JF, Lopez FG, Govern JM. The contributions of parental attachment bonds to college student development and adjustment: a meta-analytic review. J Couns Psychol. 2011;58(4):565-96. https://doi.org/1 $0.1037 / \mathrm{a} 0024635$.

53. Schunk DH. Self-efficacy and achievement behaviors. Educ Psychol Rev. 1989;1(3):173-208. https://doi.org/10.1007/BF01320134.

54. Bandura A. Self-efficacy mechanism in human agency. Am Psychol. 1982; 37(2):122-47. https://doi.org/10.1037/0003-066X.37.2.122.

55. Zhang J, Schwarzer R. Measuring optimistic self-beliefs: a Chinese adaptation of the general self-efficacy scale. Psychologia: An International Journal of Psychology in the Orient, 1995.

56. Zhang Z. Study on relapse tendency of heroin addicts. Psychol Sci. 2004 27(3):739-40.

57. Zhang K, Zhang S, Dong Y. Positive psychological capital: measurement and its relationship with mental health. Psychol Behav Stud. 2010;8(01):58-64.

58. Wen Z, Ye B. Different methods for testing moderated mediation models: competitors or backups? Acta Psychol Sin. 2014;46(5):714-26. https://doi. org/10.3724/SP.J.1041.2014.00714

59. Mackinnon DP. Introduction to statistical mediation analysis. New York: Routledge; 2008

60. Preacher K, Kelley K. Effect size measures for mediation models: quantitative strategies for communicating indirect effects. Psychol Methods. 2011;16(2):93-115. https://doi.org/10.1037/a0022658.

61. Muller $\mathrm{D}$, Judd CM, Yzerbyt VY. When moderation is mediated and mediation is moderated. J Pers Soc Psychol. 2005;89(6):852-63. https://doi. org/10.1037/0022-3514.89.6.852.

62. Hayes AF. Introduction to mediation, moderation, and conditional process analysis: a regression-based approach. J Educ Meas. 2013;51(3):335-7.

63. Wen Z, Ye B. Mediation effect analysis: methods and model development Adv Psychol Sci. 2014;22(5):731-45. https://doi.org/10.3724/SP.J.1042.2014. 00731.

64. He W, Zeng X, Lan T. Construction of psychological service system of drug rehabilitation police under the background of epidemic situation. Studies in Crime and Rehabilitation. 2020;09:48-51.
65. Bartik AW et al. Measuring the labor market at the onset of the COVID-19 crisis. 2020, National Bureau of Economic Research

66. Nagelhout GE, Hummel K, de Goeij MCM, de Vries H, Kaner E, Lemmens P. How economic recessions and unemployment affect illegal drug use: a systematic realist literature review. Int J Drug Policy. 2017;44:69-83. https:// doi.org/10.1016/j.drugpo.2017.03.013.

67. Solati K, Hasanpourdehkordi A. Study of Association of Substance use Disorders with family members' psychological disorders. I Clin Diagn Res Jcdr. 2017;11(6):VC12-5. https://doi.org/10.7860/JCDR/2017/24547.10021.

68. Spinelli MA et al. Factors associated with substance use in older homeless adults: Results from the HOPE HOME Study. other, 2017. 38(1).

69. Foster, S. and A. Robin, Family conflict and communication in adolescence. Assessment of Childhood Disorders, 1997: p. 627-682.

70. Higgins ET. Self-discrepancy: a theory relating self and affect. Psychological review. Psychol Rev. 1987:94(3):319-40.

71. Baker, T.B., Piper M.E., McCarthy D.E., Majeskie M.R., Fiore M.C., Addiction motivation reformulated: an affective processing model of negative reinforcement. Psychol Rev, 2004. 111(1): p. 33-51, 1, DOl: https://doi.org/1 0.1037/0033-295X.111.1.33

72. Carmona-Halty M, Salanova M, Schaufeli WB. The strengthening starts at home: Parent-child relationships, psychological capital, and academic performance-a longitudinal mediation analysis. Curr Psychol. 2020:1-9.

73. Ye B, et al. Family cohesion and social adjustment of chinese university students: the mediating effects of sense of security and personal relationships. Curr Psychol. 2019:1-12.

74. Liu L, Xu X, Wu H, Yang Y, Wang L. Associations of psychological capital, demographic and occupational factors with cigarette smoking among Chinese underground coal miners. BMC Public Health. 2015;15(1):20. https:/ doi.org/10.1186/s12889-015-1349-6.

75. Raesian AS, Golzari M, Borjali A. Effectiveness of hope therapy on reducing depressive symptoms and preventing of relapse in cure-seeker women with dependency to narcotic drugs. research on addiction, 2011. 5(17): p. 21-40.

76. Bandura A. Social foundations of thought and action. Englewood Cliffs, NJ. 1986;1986:23-8.

77. Repetti RL. Effects of daily workload on subsequent behavior during marital interaction: the roles of social withdrawal and spouse support. J Pers Soc Psychol. 1989;57(4):651-9. https://doi.org/10.1037/0022-3514.57.4.651.

78. Yu X et al. Positive psychology as applied to group counseling for drug abstainers. Journal of Psychological ence, 2012.

79. Lan T, Chen M, Zeng X, Liu T. The influence of job and individual resources on work engagement among Chinese police officers: a moderated mediation model. Front Psychol. 2020;11. https://doi.org/10.3389/fpsyg.2020 00497.

80. Fergus S, Zimmerman MA. Adolescent resilience: a framework for understanding healthy development in the face of risk. Annu Rev Public Health. 2005;26(1):399-419. https://doi.org/10.1146/annurev.publhealth.26. 021304.144357.

81. Rawatlal N, Kliewer W, Pillay BJ. Adolescent attachment, family functioning and depressive symptoms. S Afr J Psychiatry. 2015;21(3):80-5. https://doi. org/10.4102/sajpsychiatry.v21i3.672.

82. Lee SY, et al. Interplay of negative emotion and health self-efficacy on the use of health information and its outcomes. Commun Res. 2008;35(3):35881.

83. Basumantari S. Effect of comprehensive alternative excercise therapy in rehabilitation of drug addicts: Department of Research Development and Advanced studies; 2011

84. Mensinga J. The feeling of being a social worker: including yoga as an embodied practice in social work education. Social Work Education, 2011. 30(6): p. 650-662.

85. Zaami S, Marinelli E, Varì MR. New trends of substance abuse during COVID19 pandemic: an international perspective. Front Psychiatry. 2020;11:700. https://doi.org/10.3389/fpsyt.2020.00700.

\section{Publisher's Note}

Springer Nature remains neutral with regard to jurisdictional claims in published maps and institutional affiliations. 